\title{
Surface Mediated Hierarchical Assemblies of Highly Hydrophobic Phenylalanine-Based Peptides
}

\author{
Enric Mayans, ${ }^{[a, b]}$ Georgina Fabregat, ${ }^{[a, b]}$ Ruben Juárez, ${ }^{[a]}$ Carlos Cativiela, ${ }^{*[c]}$ Jordi Puiggalí, ${ }^{*[a, b]}$ and \\ Carlos Alemán ${ }^{\star[a, b]}$
}

\begin{abstract}
We report the noticeable control exerted by the surface in the self-assembly of a highly hydrophobic triphenylalanine peptide with fluorenyl functionalities blocking the two ends. The remarkable differences observed among the polymorphic hierarchical assemblies obtained onto silanized glass, scratched glass, stainless steel, exfoliated mica, silicon wafer, carbon, polytetrafluoroethylene, plasma-functionalized, polystyrene and nitrocellulose substrates are consequence of the balance between peptide...peptide and peptide...surface interactions. This balance is greatly influenced by the surface characteristics, as defined by the wettability (hydrophobicity or hydrophilicity) and roughness (degree of flatness and regularity). Furthermore, very stable dendritic structures, in which primary frameworks nucleated from the center grow according to a 4-fold pseudo-symmetry branching, have been obtained onto hydrophilic treated polystyrene.
\end{abstract}

\section{Introduction}

Since Reches and Gazit reported in 2003 the self-assembly of diphenylalanine (FF) into well-ordered nanotubes, ${ }^{[1]}$ small phenylalanine-based aromatic peptides have been widely studied and considered as a new class of materials owing to their structural simplicity and tunability, functional versatility, cost effectiveness, and widespread applications. ${ }^{[2-4]}$ The 9fluorenylmethoxycarbonyl (Fmoc)-protected FF derivative (Fmoc-FF) forms peptide fibrils ${ }^{[5]}$ and very stable hydrogels ${ }^{[6,7]}$ that were thought to arise from the additional $\pi$-stacking interactions induced by the Fmoc capping groups. The influence of the number of aromatic rings on the self-assembly was also examined by increasing the number of $F$ residues. Tri- and tetra-

[a] E. Mayans, Dr. G. Fabregat, R. Juárez, Prof. Dr. J. Puiggalí, Prof. Dr. C. Alemán

Departament d'Enginyeria Química, ETSEIB, Universitat Politècnica de Catalunya, Diagonal 647, 08028 Barcelona, Spain

E-mail: jordi.puiggali@upc.edu and carlos.aleman@upc.edu

[b] E. Mayans, Dr. G. Fabregat, Prof. Dr. J. Puiggalí, Prof. Dr. C. Alemán

Center for Research in Nano-Engineering, Universitat Politècnica de Catalunya, Campus Sud, Edifici C', C/Pasqual i Vila s/n, Barcelona E-08028, Spain

[c] Prof. C. Cativiela

Department of Organic Chemistry and Instituto de Síntesis Quimica y Catalisis Homogenea (ISQCH), University of Zaragoza-CSIC,

50009 Zaragoza, Spain

E-mail: cativiela@unizar.es

Supporting information for this article is given via a link at the end of the document phenylalanine (FFF and FFFF, respectively) form solid fibrillary plate-like (nanoplates) ${ }^{[8]}$ and tubular nanostructures. ${ }^{[9]}$ Fmoc-FFF self-assembles into hydrogels, ${ }^{[10]}$ whereas Fmoc-FFFF results in the formation of nanoplates, fibrils, star-like aggregates and illdefined nanospheres depending on the incubation conditions. ${ }^{[9]}$ Besides, the influence of the environmental conditions (i.e. solvent, co-solvent, temperature and concentration) on the selfassembly of FF, FFF and FFFF peptides capped with two fluorenyl functionalities has been recently reported. ${ }^{[11]}$

Analysis of the influence of environmental considerations in the self-assembly of both F-homopeptides ${ }^{[9,11]}$ and F-containing amphiphiles ${ }^{[12]}$ has evidenced the very important role played by $\pi-\pi$ staking interactions in the overall self-assembled structures. Moreover, the impact of aromatic hydrophobic interactions on the formed structures seems to be also dependent on the peptide sequence and the chemical structure of the $\mathrm{N}$ - and/or $\mathrm{C}$ terminus blocking groups. ${ }^{[13]}$ However, in addition to the environmental conditions and the chemical structure of the peptide, the solid surface used as substrate should be also considered as a key issue to control the peptide self-assembly behavior as well as the properties of the resultant micro- and/or nanostructures. Thus, the competition between peptide $\cdots$ surface and peptide...peptide interactions could be regulated through the characteristics of the surface, resulting in the formation of very different structures for the same peptide and environmental conditions.

The influence of the solid surface on the self-assembly of the Fderivatives has been exclusively investigated for the parent FF dipeptide. ${ }^{[14,15]}$ Krishnan and coworkers ${ }^{[14]}$ studied the influence of the substrate on the density, distribution and dimensions of FF nanotubes by considering poly(vinylchloride), glass, silicon, aluminum and mica substrates. ${ }^{[14]}$ Tendler and co-workers ${ }^{[15]}$ obtained tubular assemblies of FF by spin-casting 0.5-1.0 $\mathrm{mg} / \mathrm{mL}$ peptide solutions onto rough glass substrates. In contrast, tubes re-organized into dendritic structures when glass was replaced by an atomically flatter mica substrate. Nevertheless, the influence of the substrate on highly hydrophobic $F$ derivatives (i.e. homopeptides with three or more $\mathrm{F}$ residues and blocked with aromatic functionalities at the two ends) has not been examined yet.

In this work we examine the influence of the substrate in the supramolecular assemblies formed by a highly aromatic FFF derivative capped with $\mathrm{N}$ - and $\mathrm{C}$-terminal fluorenyl functionalities (Scheme 1), which has been denoted Fmoc-FFF-OFm. The remarkable influence of the substrate has been proved by comparing the structures formed onto different inorganic (silanized glass, scratched glass, stainless steel AISI 316, exfoliated mica, silicon wafer and carbon coating from 
evaporation) and organic (polytetrafluoroethylene, plasmafunctionalized polystyrene and nitrocellulose films) surfaces.<smiles>O=C(NC(Cc1ccccc1)C(=O)N[C@@H](Cc1ccccc1)C(=O)NC(Cc1ccccc1)C(=O)OCC1c2ccccc2-c2ccccc21)OCC1c2ccccc2-c2ccccc21</smiles>

Scheme 1: Fmoc-FFF-OFm

Our results indicate that initially the peptide organizes into nanofibers, as is frequently observed in highly aromatic F-based peptides. ${ }^{[9,11,16]}$ After this stage, which is dominated by peptide...peptide interactions, a very large variety of polymorphs can be subsequently formed by regulating the strength and nature of peptide $\cdots$ surface interactions. Noticeably, the impact of the surface characteristics, which has been defined through the degree of hydrophilicity / hydrophobicity and the roughness / flatness as determined by the contact angle $(\theta)$ and root-meansquare roughness $(\mathrm{Rq})$, respectively, on the hierarchical selfassembly of peptide nanofibers has been proved to be more important than the influence of the incubation conditions.

\section{Results and Discussion}

The characteristics ( $\theta$ and $\mathrm{Rq}$ ) of the different surfaces considered in this work are listed in Table 1, which also summarizes the main supramolecular structures assembled onto each one. The self-assembly was promoted by drop casting 20$50 \mu \mathrm{L}$ aliquots of peptide solution on each of the 9 above mentioned substrates and kept at room temperature or inside a cold chamber $\left(4^{\circ} \mathrm{O}\right.$ ) until dryness. Peptide concentrations ranging from 5 to $0.1 \mathrm{mg} / \mathrm{mL}$ in hexafluoroisopropanol : methanol (HFIP:MeOH) mixtures with 1:0, 99:1, 24:1, 4:1, 2:3, $1: 4,1: 9$ and $1: 49$ ratios were investigated. Although all such solution conditions were systematically tested for the nine considered substrates, results presented in this section only correspond to the conditions in which stable structures (i.e. structures that remained formed upon manipulation for optical microscopy, SEM and AFM observations) were formed. The structural variability displayed in Table 1 , which implies very different conditions, clearly reflects that the self-assembly process depends not only on the peptide-surface interactions but on the balance among the interactions present in the whole system (i.e. peptide-surface, peptide-peptide, peptide-solvent, solvent-surface and solvent-solvent).

In silanized glass the mineral surface is treated with $\mathrm{Cl}_{2} \mathrm{SiMe}_{2}$ to increase its hydrophobicity (Table 1). Drop-cast of concentrated Fmoc-FFF-OFm solutions in HFIP:MeOH onto silanized glass induce the formation of micrometric jellyfish-like structures (Figures S1a-d), which come from the hierarchical assembly of nanofibers (Figure 1a). Thus, two regions can be clearly identified in SEM micrographs: (i) the pendant-fringe, which is contact with the hydrophobic and flat surface, and consists in a dense, regular and linear packing of ultra-thin fibers; and (ii) the bell of the jellyfish-like structures, which apparently is not in contact with the substrate, and can be described as a disordered aggregation of nanofibers. The interior of the latter giant microstructures is very porous due to the random distribution of nanofibers (Figures $1 \mathrm{~b}$ and S1e).
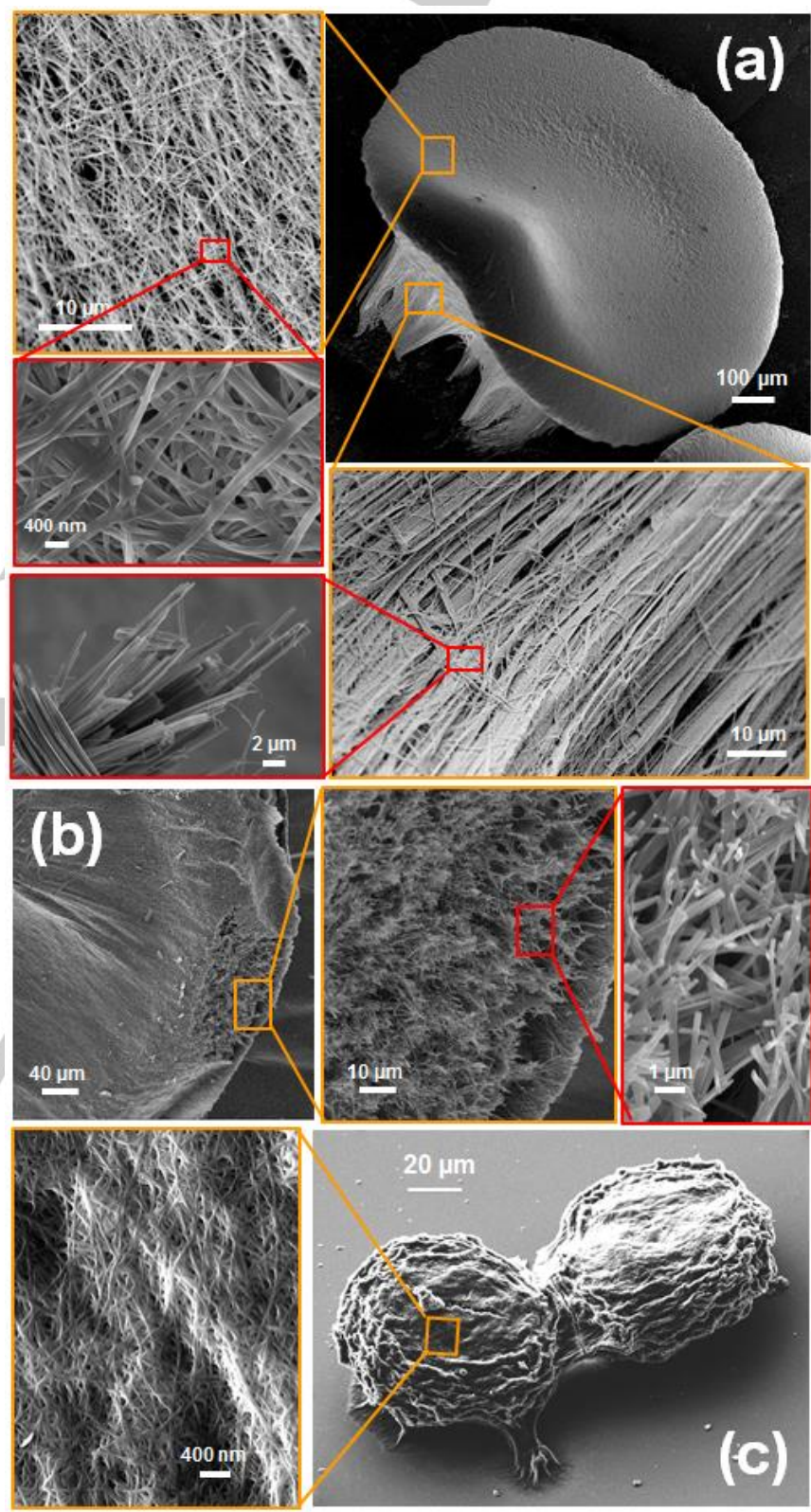

Figure 1. (a) Representative jellyfish-like structures obtained by depositing a $5.95 \mathrm{mg} / \mathrm{mL}$ Fmoc-FFF-OFm solution in 99:1 HFIP:MeOH onto silanized glass at room temperature. (b) Breakages at the bell area indicate that the interior of such structures correspond to porous and disordered assemblies of nanofibers. (c) Aggregated structures obtained using the same experimental conditions that in (a) and (b) depositing a $4.80 \mathrm{mg} / \mathrm{mL}$ peptide solution in $24: 1$ HFIP:MeOH onto silanized coverslip at $4{ }^{\circ} \mathrm{C}$. 
Table 1. Surface characteristics of the substrates used in this work: contact angle $(\theta)$ and RMS roughness $(\mathrm{Rq})$. Description of the assembled structures and required conditions is also provided.

\begin{tabular}{|c|c|c|c|}
\hline Surface & 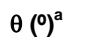 & $R q(n m)^{b}$ & Assembly characteristics \\
\hline Silanized glass & $76 \pm 2$ & $1.5 \pm 0.5$ & $\begin{array}{l}\text { - Jellyfish-like structures in } 99: 1 \\
\text { and } 24: 1 \text { HFIP:MeOH at } 25{ }^{\circ} \mathrm{C} \\
\text { and } 4^{\circ} \mathrm{C} \text {. }\end{array}$ \\
\hline Scratched glass & $58 \pm 2$ & $3.5 \pm 0.8$ & $\begin{array}{l}\text { - Stacked braid-like structures } \\
\text { growing from scratches in } 2: 3,1: 4 \\
\text { and } 1: 9 \mathrm{HFIP}: \mathrm{MeOH} \text { at both } 25 \\
\text { and } 4{ }^{\circ} \mathrm{C} \text {. } \\
\text { - Unstable dendritic-like structures } \\
\text { growing onto the glass in } 24: 1 \\
\text { (from nanofibers), } 1: 9,1: 19 \text { (from } \\
\text { ultra-thin plates) and } 1: 49 \\
\text { (branched) HFIP:MeOH at } 4{ }^{\circ} \mathrm{C} \text {. }\end{array}$ \\
\hline Steel AISI 316 & $74 \pm 7$ & $14.4 \pm 3.2$ & $\begin{array}{l}\text { - spherical assemblies forming } \\
\text { necklaces in HFIP at } 25 \text { and } 4^{\circ} \mathrm{C} \text {. }\end{array}$ \\
\hline Exfoliated mica & $<10$ & $1.3 \pm 0.4$ & $\begin{array}{l}\text { - Incipient crystalline structures in } \\
\text { 1:9 HFIP:MeOH at } 4 \stackrel{\circ}{ } \mathrm{C} \text {. } \\
\text { - Spherulites surrounded by a ring } \\
\text { of fibrous nanostructures in HFIP } \\
\text { at } 4^{\circ} \mathrm{C} \text {. }\end{array}$ \\
\hline Silicon wafer & $34 \pm 3$ & $1.6 \pm 0.7$ & $\begin{array}{l}\text { - Incipient crystalline structures in } \\
\text { 1:9 HFIP:MeOH at } 4 \stackrel{\circ}{ } \mathrm{C} \text {. } \\
\text { - Spherulites surrounded by a ring } \\
\text { of fibrous nanostructures in } 1: 49 \\
\text { HFIP:MeOH and HFIP at } 4^{\circ} \mathrm{C} \text {. }\end{array}$ \\
\hline Carbon coating & $63 \pm 7$ & $1.8 \pm 0.6$ & $\begin{array}{l}\text { - Incipient crystalline structures in } \\
\text { 1:9 HFIP:MeOH at } 4 \stackrel{\circ}{ } \mathrm{C} \text {. } \\
\text { - Spherulites surrounded by a ring } \\
\text { of fibrous nanostructures in } 1: 49 \\
\text { HFIP:MeOH and HFIP at } 4^{\circ} \mathrm{C} \text {. }\end{array}$ \\
\hline Teflon® & $112 \pm 3$ & $29 \pm 5$ & $\begin{array}{l}\text { - Large, gelatinous and poorly } \\
\text { defined peptide aggregates in } \\
\text { HFIP at } 25 \text { and } 4^{\circ} \mathrm{C} \text {. }\end{array}$ \\
\hline $\begin{array}{l}\text { Plasma-treated } \\
\text { polystyrene }\end{array}$ & $41 \pm 2$ & $8.5 \pm 4.5$ & $\begin{array}{l}\text { - Stable dendritic structures with } \\
\text { 4-fold pseudo-symmetry in HFIP } \\
\text { at } 4 \stackrel{\circ}{ } \text { (low peptide } \\
\text { concentration). } \\
\text { - Crystalline assemblies in HFIP } \\
\text { at } 4 \stackrel{\circ}{\circ} \text { (high peptide } \\
\text { concentration). }\end{array}$ \\
\hline Nitrocellulose & $34 \pm 6$ & $585 \pm 283$ & $\begin{array}{l}\text { - Well-defined crystals coexisting } \\
\text { with poorly defined spherical }\end{array}$ \\
\hline
\end{tabular}

${ }^{a}$ Average value \pm standard deviation from 15 independent measures for each sample. ${ }^{b}$ Determined by atomic force microscopy.

Eventually, two or even three fused microstructures can coexist with the jellyfish-like assembly (Figures 1c and S2). Overall, results indicate that the hierarchical assembly induced by silanized glass depend on the strength of the peptide...surface, which decreases with the distance. Similar microstructures but surrounded by poorly ordered dendritic-like assemblies (Figure S3) are obtained when the solvent evaporation is carried out in controlled environments using, for example, an hermetically sealed desiccator. Due to their particular morphology, these structures have been associated to intermediate stages of the assemblies observed in open conditions.

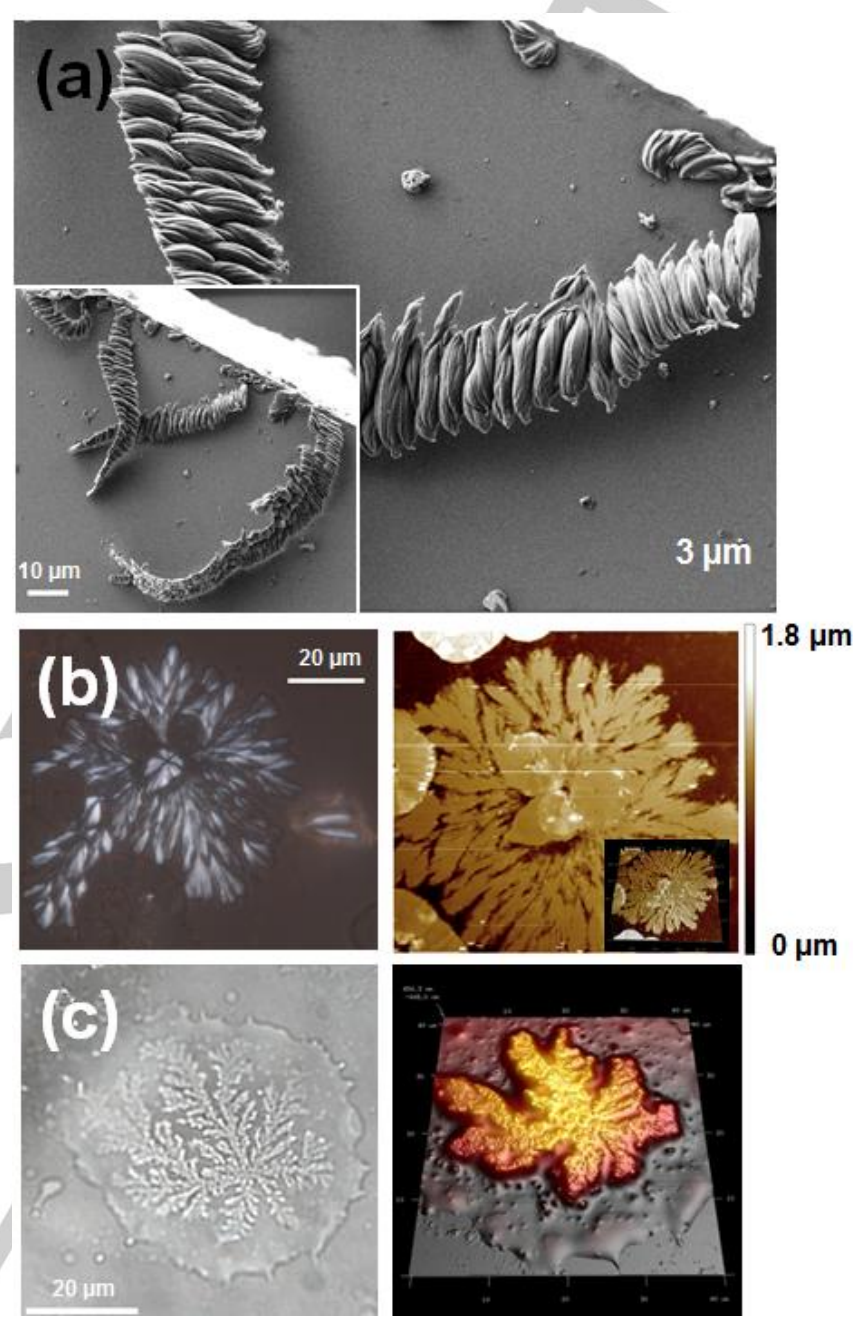

Figure 2. Representative Fmoc-FFF-OFm assemblies observed onto glass coverslip substrates at $4{ }^{\circ} \mathrm{C}$ : (a) SEM micrograph of braid-like microstructures growing from thin scratches and boundaries from a $2 \mathrm{mg} / \mathrm{mL}$ peptide solution in 2:3 HFIP:MeOH; (b) Optical microscopy, amplitude and topographic (inset) AFM micrographs of the dendritic-like structure derived from a $0.25 \mathrm{mg} / \mathrm{mL}$ solution in 1:19 HFIP:MeOH; and (c) optical micrograph and 3D topographic AFM image of the branched dendritic-like structure derived from a $0.1 \mathrm{mg} / \mathrm{mL}$ solution in 1:49 HFIP:MeOH. AFM images: (b) $60 \times 60 \mu^{2}$ and (c) $40 \times 40 \mu \mathrm{m}^{2}$.

Fmoc-FFF-OFm organizes into stacked braid-like microstructures at scratched glass coverslips (Table 1) growing from both boundaries and scratches (Figures 2 and S4), suggesting that multiple interfaces causes a complex assembly mechanism. Drop-casting of peptide solutions onto glass also results in the formation of dendritic-like structures (Figures $2 b-c$ ). The morphology of such unique assemblies, which depends on the peptide concentration and the content of co-solvent, reflects a hierarchical assembly process. Thus, in some cases they arise from the supramolecular assembly of previously formed ultrathin plates (Figure 2b) or nanofibers (Figure S5a), while other 
can be simply viewed as irregular branched structures nucleated from the center (Figures 2c and S5b-c). In any case all dendriticlike microstructures formed onto glass are highly unstable, making very difficult their manipulation. The fact that hydrophilic glass coverslips promote smaller and more unstable microstructures than silanized glass is due to the peptide...surface interactions, which compete with peptide $\cdots$ peptide interactions in the latter hydrophobic substrate but become very labile in the former one.
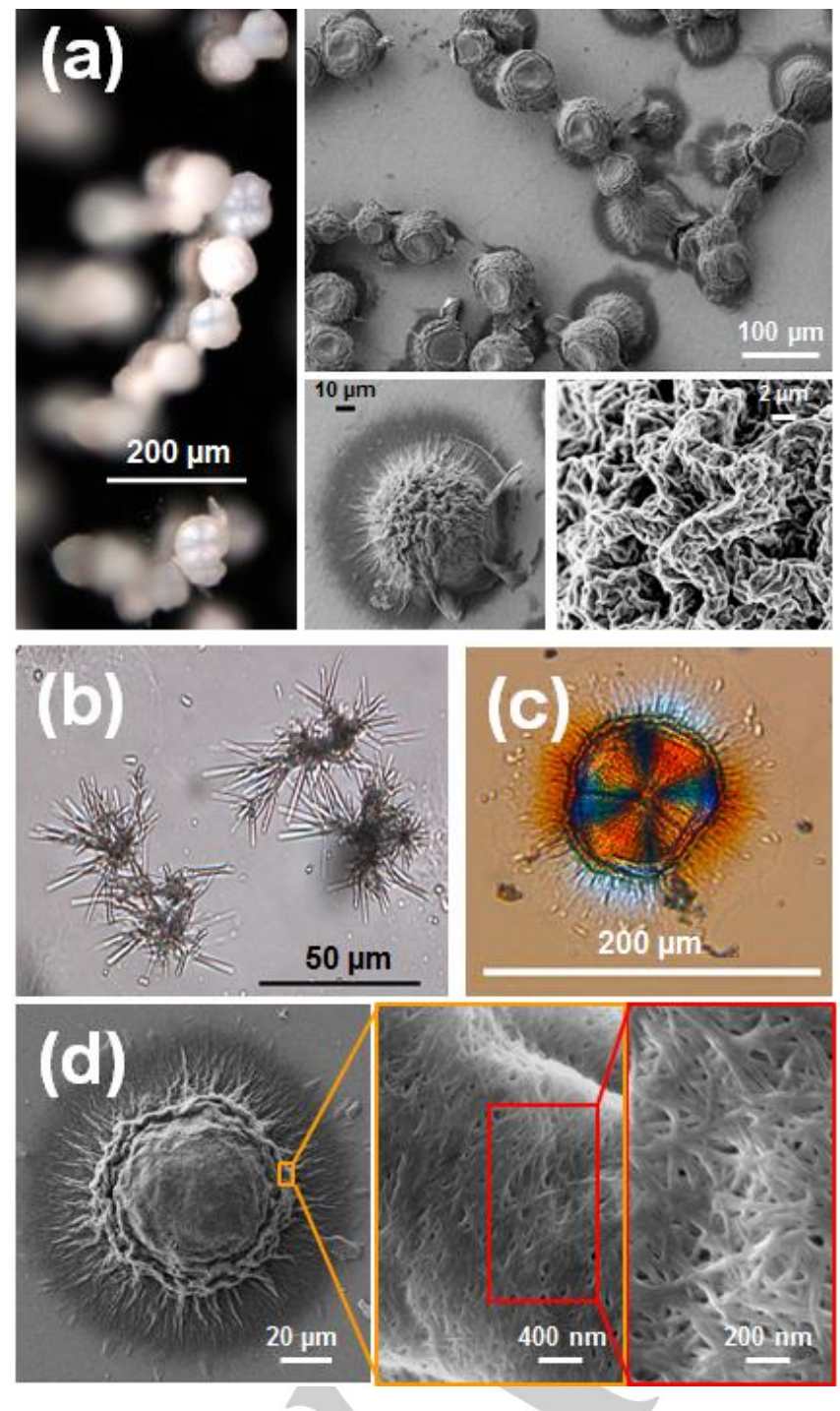

Figure 3. (a) Optical and SEM micrographs of spherical assemblies forming necklaces obtained in steel AISI 316 using a peptide concentration of $5 \mathrm{mg} / \mathrm{mL}$ in HFIP. (b) Optical micrograph of crystalline assemblies obtained in exfoliated mica using a peptide concentration of $0.5 \mathrm{mg} / \mathrm{mL}$ in $1: 9 \mathrm{HFIP}: \mathrm{MeOH}$. (c) Optical and (d) SEM micrographs of birefringent spherulites surrounded by a ring of nanofibers obtained in exfoliated mica using a $5 \mathrm{mg} / \mathrm{mL}$ peptide concentration in HFIP.

Deposition of the peptide dissolved in HFIP onto steel AISI 316 spontaneously results in the formation of spherical morphologies of $\sim 80 \mu \mathrm{m}$ diameter arranged in necklaces (Figure $3 \mathrm{a}$ ). The formation of spherical microstructures cannot be attributed to the hydrophilicity of the steel substrate, which is slightly lower than that of glass, but to the roughness (Table 1). The increment of $\mathrm{Rq}$ with respect to glass coverslips suggests a drastic change in the nucleation mechanism at the steel-peptide interface that, subsequently, affects the assembly pathways. Although apparently these microstructures do not present the branched crystalline growth, detailed inspection reveals the Maltese cross typically observed in birefringent spherulites. Microspheres observed in SEM micrographs can be defined as complex multihierarchical self-assemblies consisting on relatively porous and heterogeneous distributions of aggregates, which in turn are made of densely packed nanofibers.

Exfoliated mica favors the nucleation of incipient crystalline microstructrures (Figure 3b) for low peptide concentrations, while dense assemblies formed by birefringent spherulites surrounded by a ring of fibrous nanostructures are observed for high peptide concentrations (Figures 3c-d). Similar morphologies were obtained onto silicon wafer and carbon surfaces (Figures S6-S7), even though a difference in the organization of the spherulites was detected with respect to mica. Spherulites formed onto the latter surface are distributed individually or in small groups with two or three connected elements (Figures S8a-b), whereas onto silicon wafer and carbon spherulites arrange in necklaces (FiguresS8c-d). Although mica, silicon wafer and carbon surface are very flat surfaces (Table 1), the hydrophilicity increases as follows: carbon < silicon wafer < mica. These wetting properties are consistent with the apparition of distinctive spherulites observed onto mica, which tends to minimize peptide $\cdots$ surface interactions.

Polytetrafluoroethylene (Teflon $\AA$ ) promotes the formation of large, gelatinous and poorly defined peptide aggregates in absence of co-solvent (Figure S9a). This is fully consistent with the hydrophobic character of such organic substrate (Table 1), which promotes the very rapid deposition of peptide nanoaggregates formed in the initial solution. Accordingly, the formation of very favorable peptide $\cdots$ surface interactions inhibits subsequent hierarchical organization steps detected for other substrates.

In contrast, stable dendritic morphologies were obtained upon deposition onto plasma-treated polystyrene of $0.5 \mathrm{mg} / \mathrm{mL}$ peptide solution in HFIP at $4{ }^{\circ} \mathrm{C}$. Although a variety of dendritic morphologies was observed, as is illustrated in Figure 4, all they presented a branched architecture in which primary frameworks were nucleated from the center. This clearly and well-defined nucleation behavior is fully consistent with the hydrophilicity of the surface, which precludes a massive adsorption of the peptide through attractive peptide $\cdots$ surface interactions. After this initial nucleation stage, growing frameworks exhibit a 4-fold pseudo-symmetry, the branching angle being of $\sim 90^{\circ}$ for the primary ones and $\sim 45^{\circ}$ for those growth from the latter, evidencing a hierarchical assembly. The progressive reduction of the branching angle has been associated with the increasing importance of peptide...peptide interactions in their competition with peptide...surface ones. Furthermore, depending on the peptide concentration the plasma-functionalized polystyrene surface also promotes the formation of crystalline assemblies 
(Figure S9b), which are similar to those observed for silicon wafer and carbon coating substrates. It is worth noting that peptide...surface contacts are minimized in these crystals, reflecting again how the peptide assembly is regulated by the surface properties (Table 1). Within this context, it should be noted that plasma treatment is the method of choice for routinely incorporate oxygen-containing moieties in bioactive polystyrene surfaces to increase their hydrophilicity and promote cellpolymer interactions. ${ }^{[17]}$
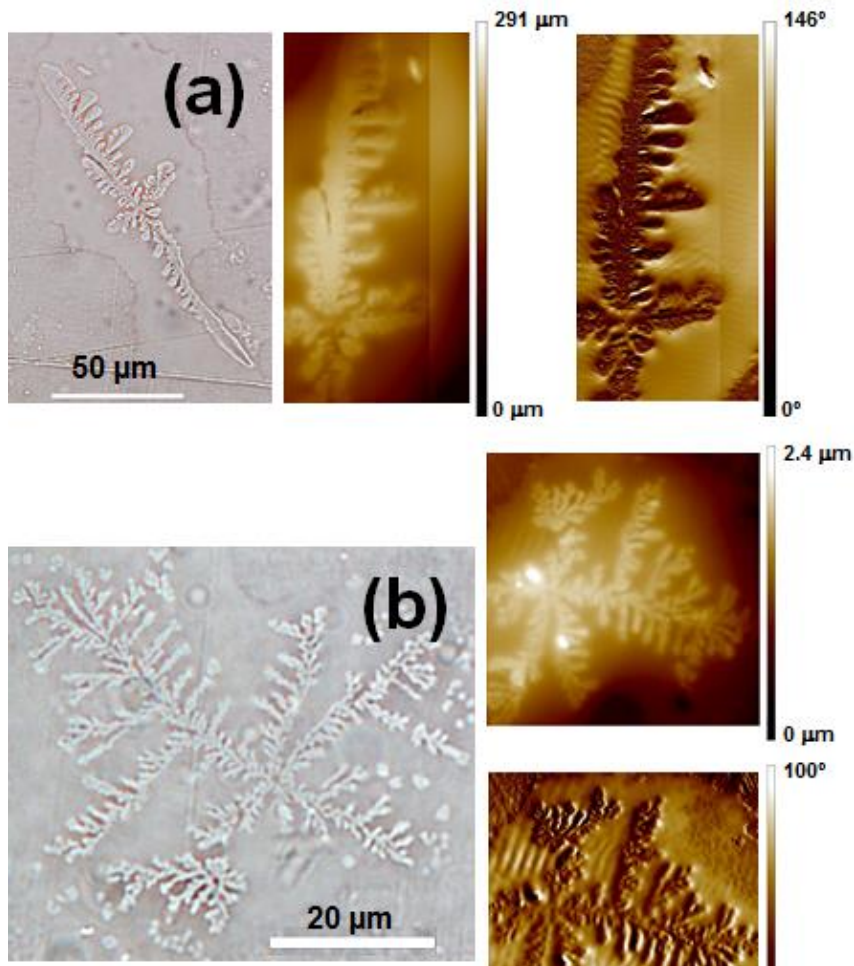

$2.4 \mu \mathrm{m}$

Figure 4. Optical micrographs and AFM images (height and phase) of representative dendritic morphologies obtained in plasma treated polystyrene using a peptide concentration of $0.5 \mathrm{mg} / \mathrm{mL}$ in HFIP at $4 \stackrel{\circ}{\circ}$. AFM images: (a) $40 \times 80 \mu^{2}$ and (b) $50 \times 50 \mu \mathrm{m}^{2}$.

Well-defined crystals coexist with poorly defined spherical biphasic morphologies onto nitrocellulose (Figure S9c-d). With respect to the other substrates studied in this work, the surface characteristics of nitrocellulose represent a unique combination: high hydrophilicity, very high roughness, and significant surface irregularity (Table 1), the latter being expressed by the high standard deviation of the Rq. Accordingly, the variety of assemblies observed for this substrate cannot be easily interpreted and has been attributed to the existence of very different interactions at different locations.

FTIR spectroscopy, which has been used to study peptidepeptide interactions, revealed that $\beta$-sheets are associated with amide I bands, which occur in the wavenumber range from 1600 $\mathrm{cm}^{-1}$ to $1700 \mathrm{~cm}^{-1}$, and arise primarily from stretching vibrations

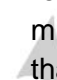
a first stage, antiparallel $\beta$-sheets are formed in solution due to the predominant role of peptide...peptide interactions with respect to peptide $\cdots$ solvent interactions. After this, supramolecular assemblies with different morphologies are formed onto the surfaces depending on the balance between peptide $\cdots$ surface and peptide $\cdots$ peptide interactions.

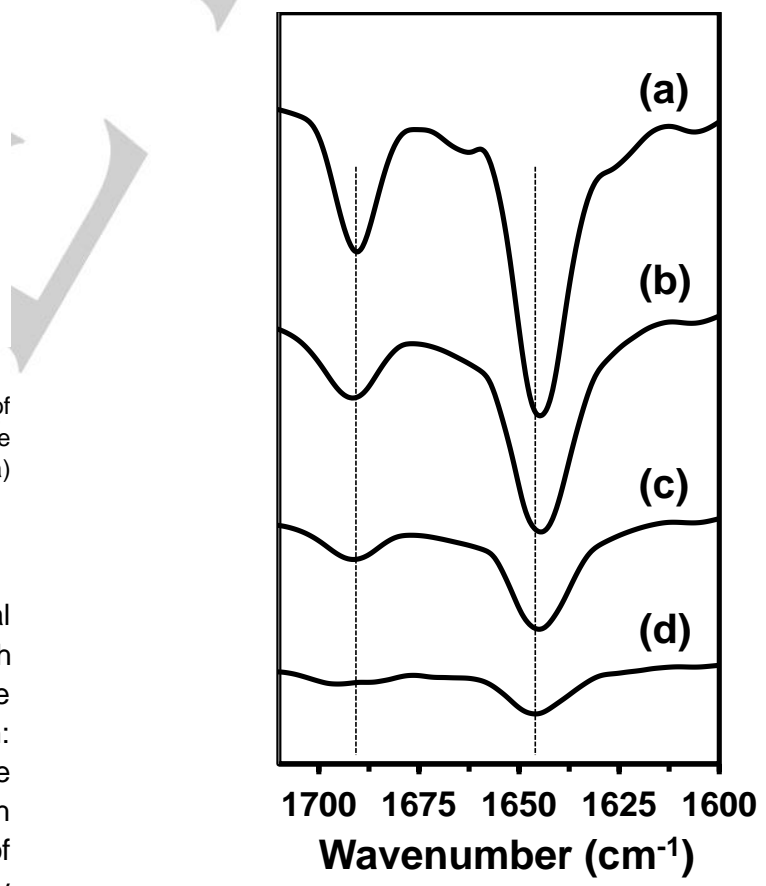

of main chain carbonyl groups. Early investigations suggested that FTIR spectroscopy might be able to distinguish between parallel from antiparallel $\beta$-sheets. ${ }^{[18-21]}$ In the latter, the amide I region displays two typical components. The major component has an average wavenumber located at $\sim 1630 \mathrm{~cm}^{-1}$, whereas the minor component appears at $\sim 1695 \mathrm{~cm}^{-1}$ is approximately five-fold weaker than the major one. The $1695 / 1630$ intensity ratio has been suggested to be proportional to the percentage of antiparallel arrangement of the $\beta$-strands in a $\beta$-sheet. For the parallel $\beta$-sheet, the amide I region displays only the major component around $1630 \mathrm{~cm}^{-1}$.

Figure 5 displays the amide I region of the FTIR spectrum recorded from a 4:1 HFIP:MeOH peptide solution. As it can be seen, the amide I region, which is characterized by two absorption peaks at 1645 and $1690 \mathrm{~cm}^{-1}$, corresponds to an antiparallel $\beta$-sheet. The spectra recorded for the assemblies formed onto the different surfaces are also associated with antiparallel $\beta$-sheets, independently of the surface characteristics and the morphology of the supramolecular structure. This is illustrated in Figure 5, which includes representative spectra of assemblies formed onto exfoliated ica, silanized glass and silicon wafer. These results indicate

Figure 5. FTIR spectra in the amide I region of (a) a 4:1 HFIP:MeOH peptide solution and peptide assemblies formed onto (b) exfoliated mica, (c) silanized glass and (d) silicon wafer using a a 4:1 HFIP:MeOH peptide solution. 
Finally, we have examined the influence of peptide-surface interactions on the peptide self-assembly when peptide-solvent, peptide-peptide and solvent-solvent are kept identical (i.e. considering identical environmental conditions in terms of solvent and peptide concentration). For this purpose, Table 2 compares the supramolecular structures observed onto the different surfaces for a $0.5 \mathrm{mg} / \mathrm{mL}$ peptide solution in $1: 9$ HFIP:MeOH. It is worth noting that in such conditions (i.e. low peptide concentration) the role played by peptide-peptide interactions in the self-assembly process is expected to be minimized with respect to that in concentrated peptide solutions. Thus, considering that peptide-solvent interactions are the same for such systems, the structural differences listed in Table 2 must be mainly attributed to the strength of peptide-surface interactions.

Table 2 Description of the assembled structures observed onto the different surfaces considered in this work using a $0.5 \mathrm{mg} / \mathrm{mL}$ peptide solution in $1: 9$ HFIP:MeOH.

\begin{tabular}{lcl}
\hline Surface & Figure & Assembly characteristics \\
\hline Silanized glass & - & - \\
Scratched glass & S4, S10a & $\begin{array}{l}\text { Stacked braid-like structures growing from } \\
\text { scratches and unstable dendritic-like } \\
\text { structures onto the glass. }\end{array}$
\end{tabular}

Steel AISI 316

Exfoliated mica

Assembled crystalline structures

Silicon wafer

S6a

Incipient crystalline structures

Carbon coating $\quad \mathrm{S} 10 \mathrm{~b}$

Incipient crystalline structures

Teflon®

Plasma-treated

S10c

Dendritic morphologies

polystyrene

Nitrocellulose

Different important features can be concluded from the observations summarized in Table 2. First, silanized glass, steel, Teflon $\AA$ and nitroceullose surfaces do not promote the systematic formation of reproducible microstructures. Silanized glass, steel and Teflon $\AA$, which exhibit a contact angle close to $90^{\circ}$ (or even higher, as is the case of Teflon $\AA$ ) are the more hydrophobic surfaces among those considered in this work (Table 1). Accordingly, in these systems hydrophobic peptidesurface interactions, which are highly attractive, dominate over peptide-peptide interactions because of the low concentration of Fmoc-FFF-OFm. Therefore, peptide molecules are widely spread onto the surface. In contrast, the lack of structuration onto hydrophilic nitrocellulose has been attributed to its surface roughness, which is an order of magnitude higher than those of all other materials examined in this study (Table 1).

On the hand, crystals resembling incipient spherulites are formed onto exfoliated mica, silicon wafer and carbon coating. Interestingly, the hydrophilicity of these surfaces is very different, decreasing from exfoliated mica $\left(\theta<10^{\circ}\right)$ to carbon coating $(\theta=$ $\left.63^{\circ} \pm 7^{\circ}\right)$. However, the three surfaces are very flat $(\mathrm{Rq}<2 \mathrm{~nm}$; Table 1), which evidence the predominant role of the flat topography with respect to the degree of hydrophilicity in the self-assembly process. Thus, after the deposition of some peptide molecules at the initial stage, attractive peptide-peptide interactions dominate over repulsive peptide-surface interactions, promoting the growing of crystals. This explanation is fully consistent with the low population of crystalline assemblies onto those surfaces. Finally, scratched glass and plasma-treated polystyrene are hydrophilic surfaces $\left(\theta=58^{\circ} \pm 2^{\circ}\right.$ and $\left.41^{\circ} \pm 3^{\circ}\right)$ with a roughness higher than those mentioned above $(\mathrm{Rq}=3.5 \pm 0.8$ and $8.5 \pm 4.5 \mathrm{~nm}$, respectively). The self-assembly onto these surfaces, which promote the formation of stacked braid-like and dendritic structures, respectively, is probably due to a delicate balance between repulsive peptide-surface and attractive peptide-peptide interactions, the formers being greatly influenced by both $\theta$ and Rq.

On the basis of the results presented in this work, we conclude that the use of substrates offer significant advantages to control the hierarchical assembly of a given peptide. Thus, the hierarchical assembly of peptides is usually regulated by modulating peptide $\cdots$ peptide and peptide $\cdots$ solvent interactions through the peptide concentration and environmental polarity, respectively.[11] Application of this conventional regulation procedure frequently permits to induce several organized and well-defined assemblies for a given peptide. However, both the number and variety of peptide supramolecular structures increase significantly when controlled peptide...surface interactions are introduced through the surface-mediated hierarchical assembly. Thus, peptide...surface interactions regulate not only the deposition of the peptide onto the substrate but also the relative importance of the peptide...peptide interactions on the self-assembly process.

\section{Conclusions}

We have shown that Fmoc-FFF-OFm is able to adopt a large variety of self-assembled microstructures by controlling the substrate. Our results indicate that in a first stage, which probably occurs in solution, highly hydrophobic F-based peptides tend to organize forming nanofibers. After this, the hierarchical assembly of such nanofibers is profoundly affected by the roughness and, specially, the degree of hydrophilicity / hydrophobicity of the substrate. Our results clearly indicate that favorable peptide $\cdots$ surface interactions provided by hydrophobic surfaces tend to prevent the formation of supramolecular structures, whereas the unfavorable interactions induced by hydrophilic surfaces enhance the role of peptide...peptide interactions, promoting the hierarchical formation of supramolecular assemblies. In addition, the formation of organized assemblies is also precluded in surfaces with very high surface roughness. Overall, peptide...peptide interactions (controlled by the peptide concentration), peptide...surface interactions (controlled by the hydrophobicity / hydrophilicity of the surface) and the surface roughness are crucial factors for defining the shape, dimensions and stability of the hierarchical 
assemblies. Within this context, the ability of plasma treated polystyrene for stabilizing well-defined dendritic structures is particularly striking. The wide range of available surfaces offers a valuable tool for the development of bionanotechnological applications based on hierarchical peptide assemblies.

\section{Acknowledgements}

Authors thank supports from MINECO and FEDER (MAT201569367-R, MAT2015-69547-R and CTQ2013-40855-R) and Gobierno de Aragón - Fondo Social Europeo (research group E40). Support for the research of C.A. was received through the prize "ICREA Academia" for excellence in research funded by the Generalitat de Catalunya.

\section{Supporting Information Summary}

Experimental methods, complementary micrographs obtained using optical and electron scanning microscopy, and complementary AFM images are provided in the Supporting Information.

Keywords: Dendrimers; Hydrophobic peptides; Self-assembly; Supramolecular organization; Surface interactions

[1] M. Reches, E. Gazit, Science 2003, 300, 625-627

[2] X. Yan, P. Zhu, J. Li, Chem. Soc. Rev. 2010, 39, 1877-1890.

[3] I. W. Hamley, Angew. Chem. Int. Ed. 2014, 53, 6866-6881.

[4] A. Lakshmanan, S. Zhang, C. A. E. Hauser, Trends Biotech. 2012, 30, 155-165.
[5] N. Amdursky, E. Gazit, G. Rosenman, Adv. Mater. 2010, 22, $2311-$ 2315

[6] J. Raeburn, C. Mendoza-Cuenca, B. N. Cattoz, M. A. Little, A. E. Terry, A. Cardoso, P. C. Griffiths, D. J. Adams, D. J. Soft Matter 2015, 11 927-935.

[7] V. Jayawarna, M. Ali, T. A. Jowitt, A. F. Miller, A. Saiani, J. E. Gough, R V. Ulijn, Adv. Mater. 2006, 18, 611-614.

[8] P. Tamamis, L. Adler-Abramovich, M. Reches, K. Marshall, P. Sikorski, L. Serpell, E. Gazit, G. Archontis, Biophys. J. 2009, 96, 5020-5029.

[9] E. Mayans, G. Ballano, J. Casanovas, A. Díaz, M. M. Pérez-Madrigal, F. Estrany, J. Puiggalí, C. Cativiela, C. Alemán, Chem. Eur. J. 2015, 21, 16895-16905.

[10] L. Chronopoulou, S. Lorenzoni, G. Masci, M. Dentini, A. R. Togna, G. Togna, F. Bordi, C. Palocci, Soft Matter 2010, 6, 2525-2532.

[11] E. Mayans, G. Ballano, J. Casanovas, L. J. del Valle, M. M. Pérez Madrigal, F. Estrany, A. I. Jiménez, J. Puiggalí, C. Cativiela, C. Alemán, Soft Matter 2016, 12, 5475-5488.

[12] J. Raeburn, A. Z. Cardoso, D. J. Adams, Chem. Soc. Rev., 2013, 42, 5143-5156

[13] S. Flemming, R. V. Ulijn, Chem. Soc. Rev., 2014, 43, 8150-8177.

[14] P. Kumaraswamy, R. Lakshmanan, S. Sethuraman, U. M. Krishnan, Soft Matter 2011, 7, 2744-2754.

[15] V. V. Korolkov, S. Allen, C. J. Roberts, S. J. B. Tendler, Faraday Discuss. 2013, 166, 257-267.

[16] C. Diaferia, F. A. Mercurio, C. Giannini, T. Sibillano, G. Morelli, M Leone, A. Accardo, Sci. Rep. 2016, 6, 26638.

[17] T. G. van Kooten, H. T. Spijker, H. J. Busscher, Biomaterials 2004, 25, 1735-1747.

[18] C. Toniolo, M. Palumbo, Biopolymers 1977, 16, 219-224.

[19] S. Krimm, J. Bandekar, Adv. Protein Chem. 1986, 38, 181-364.

[20] R. Khurana, A. L. Fink, Biophys. J. 2000, 78, 994-1000.

[21] E. Goormaghtigh, V. Cabiaux, J.-M. Ruysschaert, Subcell. Biochem. 1994, 23, 329-362. 


\section{Entry for the Table of Contents}

\section{FULL PAPER}

The control exerted by the surface in the self-assembly of a highly hydrophobic triphenylalanine peptide has been analyzed. Favorable peptide $\cdots$ surface interactions provided by hydrophobic surfaces tend to prevent the formation of supramolecular structures, whereas the hydrophilic surfaces enhance the role of peptide.. peptide interactions, promoting the hierarchical formation of supramolecular assemblies. Moreover, the formation of organized assemblies is also precluded in surfaces with very high surface roughness.

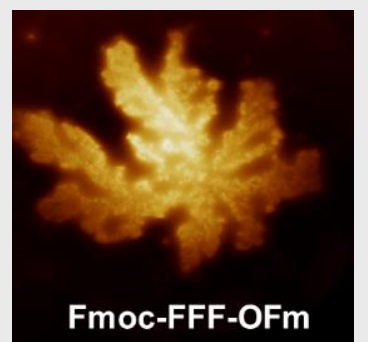

Enric Mayans, Georgina Fabregat, Ruben Juárez, Carlos Cativiela," Jordi Puiggalí, ${ }^{*}$ and C. Alemán*

Page No. - Page No.

Surface Mediated Hierarchical Assemblies of Highly Hydrophobic Phenylalanine-Based Peptides 